
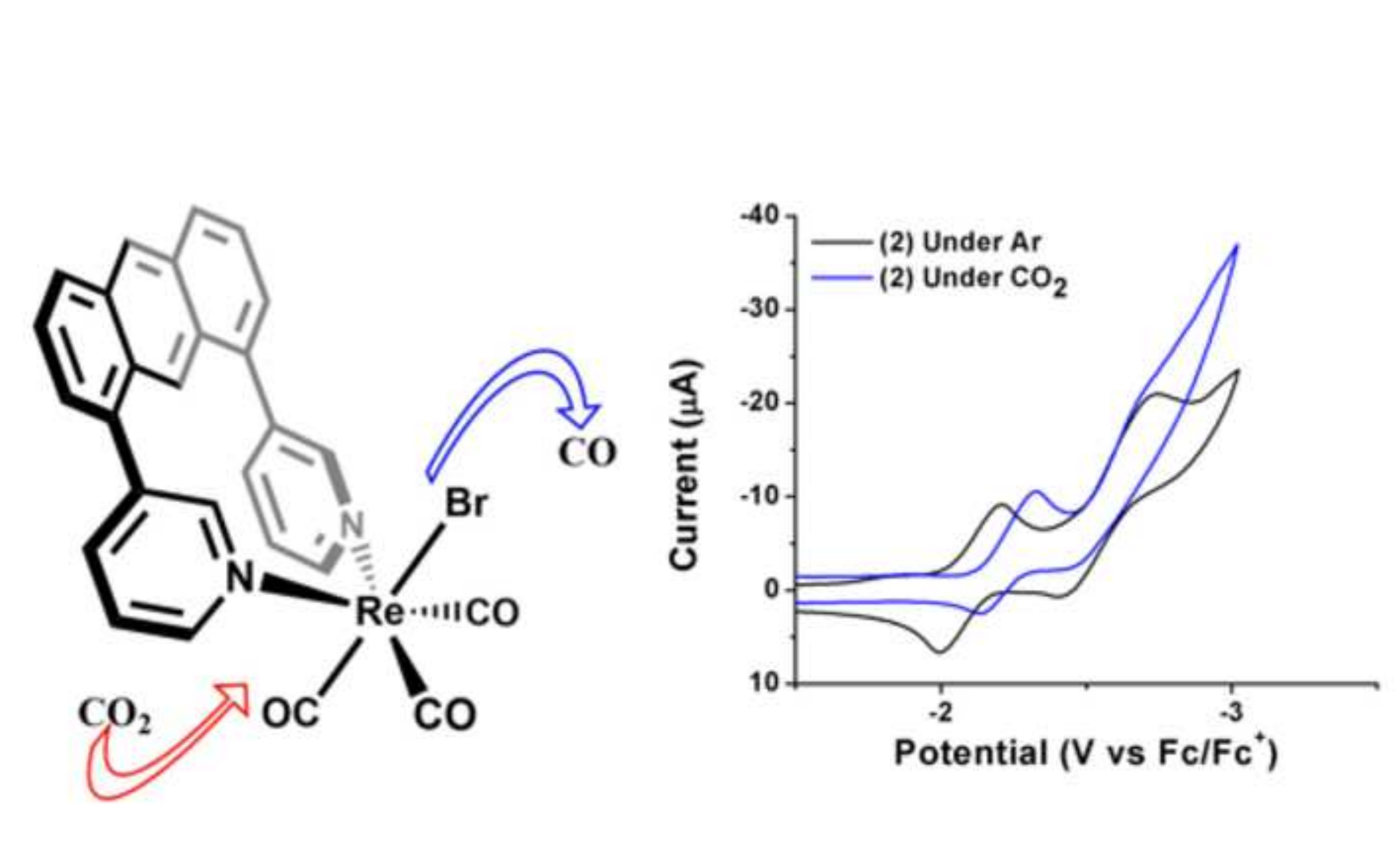

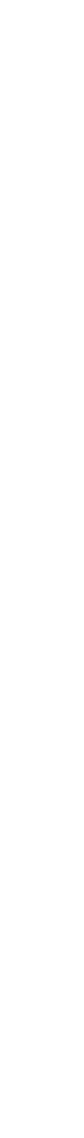




\title{
Redox Properties of a Bis-Pyridine Rhenium Carbonyl Derived from an Anthracene Scaffold
}

\author{
Taylor A. Manes and Michael J. Rose* \\ The University of Texas at Austin; Austin, TX 78712
}

*corresponding author: mrose@cm.utexas.edu

$$
+1(512) 471-4456
$$




\begin{abstract}
We report the synthesis of a novel bis-pyridine chelate derived from an anthracene scaffold. Complexation of the N2 ligand with rhenium carbonyl affords the Re tricarbonyl bromide complex [(Anth-N2)Re(CO) $\left.)_{3} \mathrm{Br}\right]$. In THF solution, the title complex exhibits two quasireversible reductions located near -2.1 and $-2.5 \mathrm{~V}$ vs $\mathrm{Fc} / \mathrm{Fc}^{+}$, which are similar to those observed in the free Anth-N2 ligand, which suggests the non-innocent behavior of the complexed anthracene scaffold. Under $\mathrm{CO}_{2}$ atmosphere, the title complex exhibits an electrocatalytic response consistent with $\mathrm{CO}_{2} \rightarrow \mathrm{CO}$ reduction, and the presence of electrocatalytically generated $\mathrm{CO}$ was confirmed by bulk electrolysis. These results suggest that alternate locations of redox activity (other than at the Re metal center, pyr donors, or bpy framework) can lead to interesting electrochemical behavior.
\end{abstract}




\section{Communication}

In an ideal energy utilization paradigm, the carbon dioxide $\left(\mathrm{CO}_{2}\right)$ produced by biological and industrial processes would be balanced with the $\mathrm{CO}_{2}$ consumed by biological processes and industrial needs.[1-5] With industrial processes increasing in size and output, and global population continually growing, the amount of $\mathrm{CO}_{2}$ in the atmosphere continues to increase and climate change continues to be a pressing issue in science and society. To be a viable contributor to a 'greener' energy landscape, a renewable energy source must be able to produce large quantities of electricity or fuel and have long term storage capabilities.[6] Wind and solar power produce large amounts of electricity but only intermittently and do not have sustainable long term storage options and since grid storage is not available there is a trade-off between batteries and supercapacitors. Batteries have a high energy density but limited lifetimes, and supercapacitors have low energy density.[7] A solution to this problem would be chemical storage. The combination of processes such as water oxidation, hydrogen generation, solar power, and $\mathrm{CO}_{2}$ reduction could produce an artificial photosynthetic device to generate a carbon neutral fuel source.[8] Such a $\mathrm{CO}_{2}$ to $\mathrm{CO}$ process could be beneficial for production of syngas, but direct reduction to methanol is preferable to generate liquid fuels.[9-12] Current challenges to the electrochemical reduction of $\mathrm{CO}_{2}$ include large overpotentials[13] and poor selectivity.[14] Thus on the molecular catalyst front, the focus of much recent work has been to address both the efficiency and selectivity of the catalytic process for $\mathrm{CO}_{2} \rightarrow \mathrm{CO}$ conversion by employing new modifications to the catalytic system by means of ionic liquids, $[15,16]$ as well as employing novel ligand designs to support rhenium and other metal centers for electrocatalysis. 


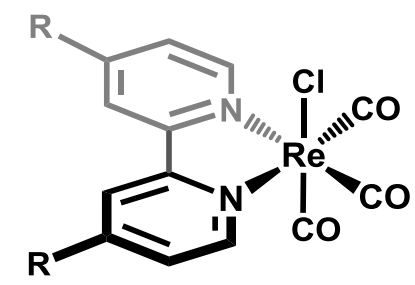

Figure 1. The original Lehn catalyst[17] $\left[\mathrm{Re}(\mathrm{bpy})(\mathrm{CO})_{3} \mathrm{Cl}\right]$ with 4,4 ' $\mathbf{R}$ group substitutions related to recent reports.[18,19]

Rhenium bis-pyridine carbonyl complexes have become the 'gold standard' for the $\mathrm{CO}_{2}$ reduction catalysts due to their high turnover rates, turnover numbers and faradaic efficiencies.[1,8,20] Lehn et al.[17] studied the reduction of $\mathrm{CO}_{2}$ to $\mathrm{CO}$ using the [fac(bpy) $\left.\operatorname{Re}(\mathrm{CO})_{3} \mathrm{Cl}\right]$ catalyst that has since been the focus of many studies regarding the mechanism elucidation and selectivity optimization during the catalytic process. More recently Kubiak et al.[21] reported several common degradation pathways in the catalytic process, one of which is the formation of the $\operatorname{Re}_{2}$ dimer, which occurs slowly once the halide is reductively eliminated from the metal center upon reductive treatment. To solve this problem, more recent work from the same group has successfully employed the use of bulky substituents at the 2 and 2' positions on the bipyridine framework.[12] Substitution studies have been performed related to Re-bpy complexes to determine if similar catalysis occurs upon modulating the strength of the ligand field.[9] However, there are presently no reports that investigate the effect of orientation of the pyridine donors (with respect to the equatorial plane of the Re center), nor are there reports regarding alternate modes of displaying the bidentate array of pyridine donors. In this Communication, we report an isoelectronic bis-pyridine Re carbonyl complex with interesting, non-innocent redox features that may participate in the $\mathrm{CO}_{2} \rightarrow \mathrm{CO}$ conversion process. 
The synthesis of the bis-pyridine ligand was performed in three steps (see Scheme 1). Starting from 1,8-dichloroanthraquinone, successive reductions using $\mathrm{NaBH}_{4}$ afforded 1,8-dichloroanthracene in good yields.[22,23] Suzuki coupling catalyzed by XPhos/[Pd(dba $\left.)_{2}\right]$ with two equivalents of 3-pyridinyl boronic acid in $\mathrm{THF} / \mathrm{H}_{2} \mathrm{O}$ generated the final product, Anth-N2 (1), in $80 \%$ yield as a yellow powder.

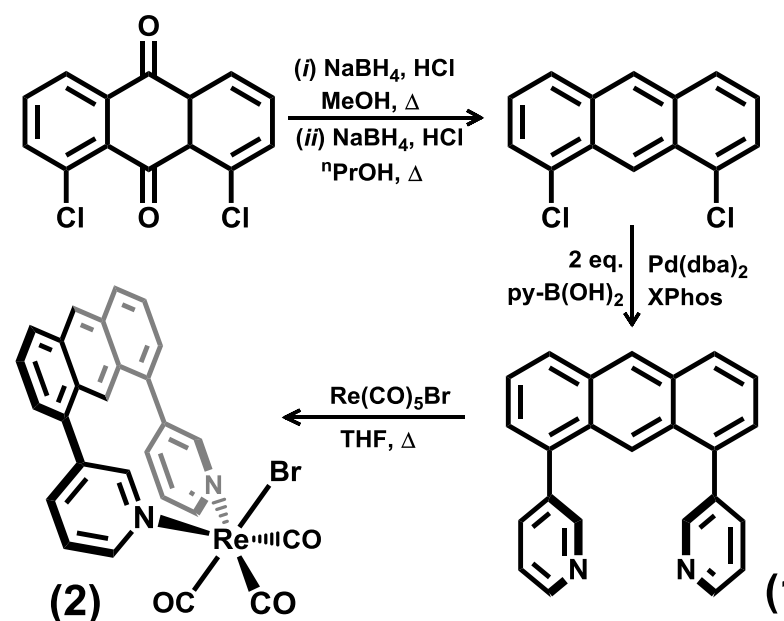

(1)

Scheme 1. Synthesis of the ligand Anth-N2 (1) and the corresponding complex $\left[(\right.$ Anth- 2$\left.) \operatorname{Re}(\mathrm{CO})_{3} \mathrm{Br}\right](\mathbf{2})$.

Under inert atmosphere, a 1:1 ratio of Anth- $\mathrm{N} 2$ and $\left[\mathrm{Re}(\mathrm{CO})_{5} \mathrm{Br}\right]$ were heated in THF (Scheme 1) to afford pure product as a bright yellow powder in good yield (48\%). The infrared spectrum of the product confirmed formation of the $\left\{\operatorname{Re}(\mathrm{CO})_{3}\right\}^{+}$moiety, evidenced by bound CO features at 2025, 1886, and $1872 \mathrm{~cm}^{-1}$. The CO stretches observed in 2 coincide reasonably with the stretches seen at 2019 and $1907 \mathrm{~cm}^{-1}$ in the $\operatorname{Re}($ bpy) congeners.

Yellow needles of $\left[(\right.$ Anth- $\left.\mathrm{N} 2) \operatorname{Re}(\mathrm{CO})_{3} \mathrm{Br}\right](2)$ were grown using vapor effusion of a DCM solution of the complex into $n$-hexane, and the resulting crystal structure is depicted in Figure 2. The binding of the Re tricarbonyl fragment to the Anth-N2 is analogous to 
that of the Re-bpy family of complexes. A key difference in the present complex is the torsion angles exhibited by the pyridine donors. The anthracene-appended pyridine donors are displaced from the plane of the anthracene backbone and when complexed with the Re carbonyl fragment the torsion ranges from $45 \cdot 0-48.1^{\circ}$. The close positioning of the donor atoms promotes the cis binding motif rather than trans orientation, and facilitates sufficient rotation of the pyridine moiety for monometallic binding. The bite angle of the Anth-N2 ligand is $86.9^{\circ}$ compared to the more acute $\sim 75^{\circ}$ reported in $\operatorname{Re}$ (bpy) complexes. The $\mathrm{Re}-\mathrm{N}$ distances of 2.247(3) and 2.242(3) $\AA$ are similar to the $\sim 2.20 \AA$ A distances seen in the Re(bpy) system.[24]

Electrochemical studies were performed on 1 (N2 ligand) and 2 (Re complex) to determine their redox activities. The cyclic voltammogram of the free ligand 1 (Figure 3, black line) exhibits two quasi-reversible features -2.20 and $-2.64 \mathrm{~V}$ vs $\mathrm{Fc} / \mathrm{Fc}^{+}$. The cyclic voltammogram of 2 (Figure 3, red line) exhibits similar reversible features at -2.10 and $2.58 \mathrm{~V} \mathrm{vs} \mathrm{Fc} / \mathrm{Fc}^{+}$that are quite similar to those of the free ligand. The peak currents in the $\mathrm{CV}$ follow a scan rate dependence that is linear with $\bigvee_{v}$ (insets, Figures 3 and 4). The more positive features in the CVs of both the free ligand and the rhenium complex show redox events similar to that reported for anthracene.[25] For comparison, a cyclic voltammogram of 1,8-dichloroanthracene was obtained (Figure 3, grey line; and Figure $\mathrm{S} 3$, Supporting Information). A single redox event at $-2.23 \mathrm{~V}$ vs $\mathrm{Fc} / \mathrm{Fc}^{+}$occurs, suggesting that the more positive peaks observed for free ligand and metal complex emanate from an anthracene-based redox event. The more negative peak that occurs in the free ligand and metal complex is not observed for 1,8-dichloroanthracene, suggesting that the feature is due to a pyridine-based redox event. Rhenium-based redox events were not 
observed. The more negative wave observed in the CV of free ligand $\mathbf{1}$ exhibits greater irreversibility $\left(i_{\mathrm{pa}} / i_{\mathrm{pc}}=0.39\right)$, compared to the analogous redox process in the Re complex $2\left(i_{\mathrm{pa}} / i_{\mathrm{pc}}=0.72\right)$. This change in reversibility may indicate enhanced electronic communication between two pendant pyridine moieties due to the conjoining Re metal center.

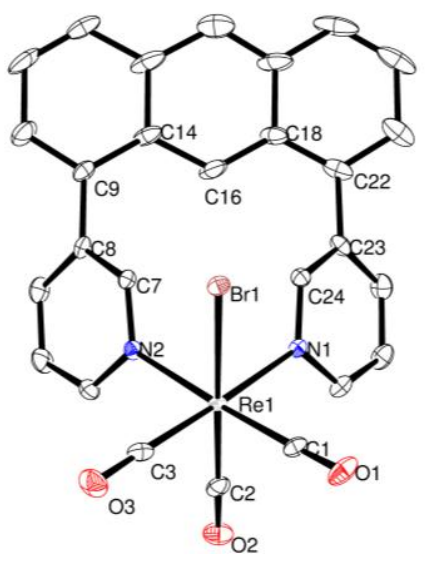

Figure 2. ORTEP diagram (30\% ellipsoids) of the molecular structure of $\left[\operatorname{Re}\left(\right.\right.$ Anth-N2) $\left.(\mathrm{CO}){ }_{3} \mathrm{Br}\right]$ (2); H atoms have been omitted for clarity. Selected bond distances $(\AA)$ : $\operatorname{Re}_{1}-\mathrm{N}_{1}=2.247(3), \operatorname{Re}_{1^{-}}$ $\mathrm{N}_{2}=2.242(3), \mathrm{Re}_{1}-\mathrm{C}_{1}=1.931(4), \mathrm{Re}_{1}-\mathrm{C}_{2}=1.922(5), \mathrm{Re}_{1}-\mathrm{C}_{3}=1.923(5), \mathrm{C}_{1}-\mathrm{O}_{1}=1.138(5), \mathrm{C}_{2}-\mathrm{O}_{2}$ $=1.115(5), \mathrm{C}_{3}-\mathrm{O}_{3}=1.135(5)$. Selected angles (deg): $\mathrm{N}_{1}-\mathrm{Re}_{1}-\mathrm{N}_{2}=87.23(12), \mathrm{N}_{1}-\mathrm{Re}_{1}-\mathrm{C}_{1}=$ 92.52(15), $\mathrm{N}_{2}-\mathrm{Re}_{1}-\mathrm{C}_{3}=89.91(15), \mathrm{C}_{1}-\mathrm{Re}_{1}-\mathrm{C}_{3}=90.32(18)$ Selected torsion angles (deg): $\mathrm{C}_{7}-\mathrm{C}_{8^{-}}$ $\mathrm{C}_{9}-\mathrm{C}_{14}=48.2(6), \mathrm{C}_{18}-\mathrm{C}_{22}-\mathrm{C}_{23}-\mathrm{C}_{24}=48.0(6)$.

Given the novel redox properties of $\mathbf{2}$ compared with Re-bpy complexes, CV experiments were performed under $\mathrm{CO}_{2}$ atmosphere (Figure 4). First, a shift of the peak near $-2.12 \mathrm{~V}$ to a more negative potential of $-2.24 \mathrm{~V}$ vs $\mathrm{Fc} / \mathrm{Fc}^{+}$is observed. Second, a marked increase in current is observed at $-2.62 \mathrm{~V} \mathrm{vs} \mathrm{Fc} / \mathrm{Fc}^{+}$, along with a complete loss of reversibility. Both of these features are hallmarks of electrocatalytic $\mathrm{CO}_{2}$ reduction by 
a molecular catalyst of this type. $[8,26]$ This phenomenon provided a framework to continue the investigation by controlled potential electrolysis (CPE).

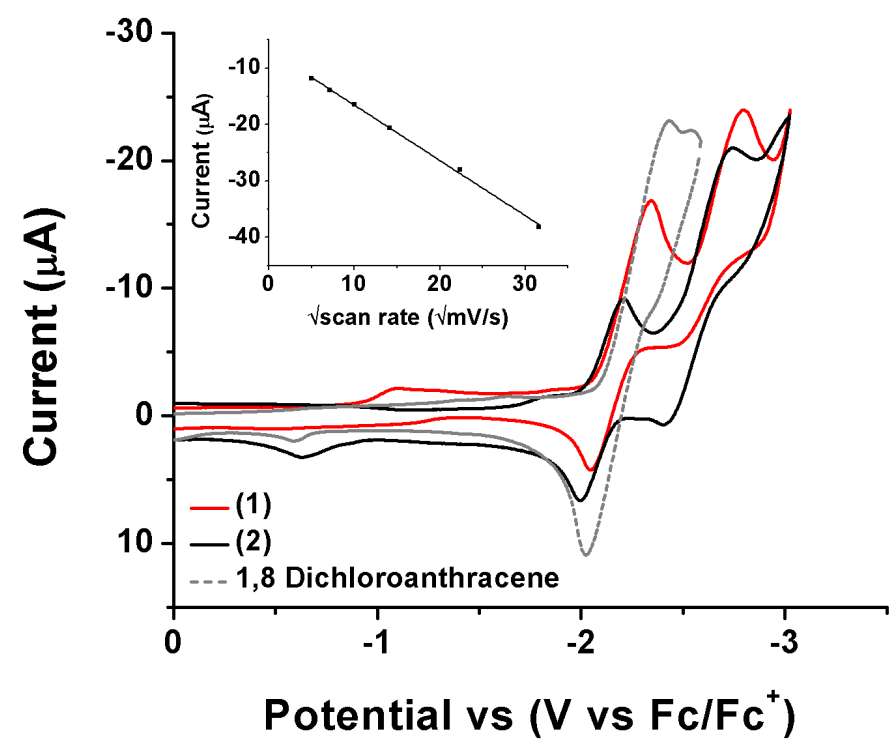

Figure 3. Cyclic voltammograms of $1 \mathrm{mM}$ 1,8-dichloroanthracene (blue line), (Anth-N2) (1, black line) and [(Anth-N2) $\left.\operatorname{Re}(\mathrm{CO})_{3} \mathrm{Br}\right]\left(2\right.$, red line) in THF with $0.1 \mathrm{M} \mathrm{TBAPF}_{6}$ as supporting electrolyte under $\mathrm{N}_{2}$ atmosphere. Inset: Scan rate dependence of the reversible reduction wave of (1) at $-2.34 \mathrm{~V}$. Experiment conditions: scan rate, $100 \mathrm{mV} / \mathrm{s}$; WE, glassy carbon $(3 \mathrm{~mm})$; $\mathrm{CE}, \mathrm{Pt}$ wire; RE, Ag wire pseudo-reference; all potentials were converted to $\mathrm{Fc} / \mathrm{Fc}^{+}$by inclusion of $\mathrm{Fc}$ in the final scan (not shown).

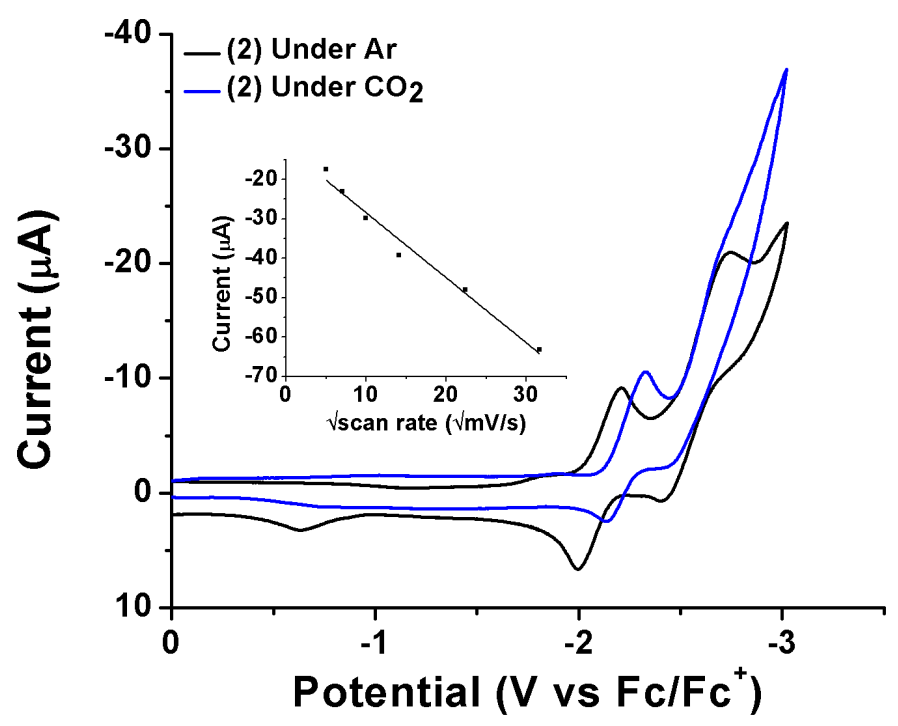

Figure 4. Cyclic voltammograms of $1 \mathrm{mM}\left[(\right.$ Anth- $\left.\mathrm{N} 2) \operatorname{Re}(\mathrm{CO})_{3} \mathrm{Br}\right](2)$ under argon (black line) or $\mathrm{CO}_{2}$ (blue line) in THF with $0.1 \mathrm{M} \mathrm{TBAPF}_{6}$ as supporting electrolyte. Inset: Scan rate 
dependence of the reversible reduction wave of (2) at $-2.74 \mathrm{~V}$. Experiment conditions: scan rate, $100 \mathrm{mV} / \mathrm{s}$; WE, glassy carbon (3 mm); CE, Pt wire; RE, Ag wire pseudo-reference; all potentials were converted to $\mathrm{Fc} / \mathrm{Fc}^{+}$by inclusion of $\mathrm{Fc}$ in the final scan (not shown).

Bulk electrolysis experiments under $\mathrm{CO}_{2}$ (1 atm) were carried out in a two compartment, H-cell two compartment cell with a glassy carbon rod working electrode, platinum mesh counter electrode, and Ag wire reference electrode. The silver electrode was separated with a vycor tip. For comparison, the widely accepted $\left[\operatorname{Re}(b p y)(C O){ }_{3} \mathrm{Br}\right]$ complex $(\mathrm{FY} \approx 95 \%) \cdot[16-18,26]$ was standardized in the above apparatus $(-2.1 \mathrm{~V}$ vs $\mathrm{Ag}$ for $1.5 \mathrm{~h}$ ) in a $\mathrm{CO}_{2}$ saturated MeCN solution with GC headspace analysis directly after the electrolysis. As reported previously, the presence or absence of $\mathrm{MeOH}$ did not greatly affect the $\mathrm{CO}_{2} \rightarrow \mathrm{CO}$ conversion efficiency for the $\mathrm{Re}(\mathrm{bpy})$ system. [26]

In contrast, the title Re complex 2 was strongly affected by the presence of $\mathrm{MeOH}$. The production of $\mathrm{CO}$ by 2 by $\mathrm{CPE}(-2.5 \mathrm{~V}$ vs $\mathrm{Ag}, 1.5 \mathrm{~h})$ in a $\mathrm{CO}_{2}$ saturated THF solution $(\sim 0.5 \mathrm{M} \mathrm{TBAPF}$ ), was first analyzed in the absence of a proton source yielding no production of $\mathrm{CO}$. In contrast, addition of $10 \mathrm{M} \mathrm{MeOH}(40 \% \mathrm{v} / \mathrm{v})$, complex 2 produced $0.57 \mu \mathrm{mol}$ of $\mathrm{CO}$, corresponding to $20 \%$ Faradaic efficiency. The sub-optimal efficiency (compared to the Re-bpy system) may be due to a lack of facile electronic communication between the two pyridine moieties (not co-planar, and no direct $\mathrm{C}-\mathrm{C}$ bond) compared with the standard Re-bpy complexes. The bpy system is known to be a highly efficient electron sink for multiple electron processes.[8,27] The conjugated $\pi$ system of the coplanar bpy allows for greater delocalization of the electron (compared to more angled pyridines on the anthracene scaffold), and the alignment with the $\operatorname{Re} d_{\pi}$ orbitals may allow for facile movement back to the metal center. Lastly, the anthracene electron 
reservoir may be too far from the metal center to act as an efficient electron transfer agent during catalysis.

In conclusion, we have constructed a novel anthracene scaffold that displays a metalinked, cis-coordinating bis-pyridine motif in alternate fashion compared to the standard bpy ligand. The Anth-N2 ligand supports a stable Re tricarbonyl complex, which exhibits redox behavior not unlike the free ligand, suggesting the anthracene scaffold acts as a pendant electron reservoir during redox and electrocatalytic experiments. Compared to the 'gold standard' Re(bpy) system, the present system exhibits an inefficiency that may be due to the distance from the metal center to the scaffold, and/or a break in conjugation between the ligating pyridine moieties. Future work will endeavor to better align the redox features of the supporting scaffold and the catalytically active event, with the aim of elaborating the scope and efficiency of available multi-electron transformations. Enhancing the rotational flexibility of the pyridine moieties may also lead to better orbital overlap with the metal center.

\section{Acknowledgements}

The authors gratefully acknowledge funding from the Robert A. Welch Foundation (F1822), the ACS Petroleum Research Fund (53542-DN13) and the US Office of Naval Research (N00014-13-10530). We also thank Prof Allen Oliver (Notre Dame Univ) and Prof Jeanette Krause (Univ of Cincinnati) for X-ray data collection at the Advanced Light Source, and we acknowledge Dr Vince Lynch for assistance with analysis of single crystal X-ray diffraction data. Crystallographic data for 2 were collected through the SCrALS (Service Crystallography at the Advanced Light Source) program at Beamline 11.3.1 at the Advanced Light Source (ALS), Lawrence Berkeley National Laboratory. The Advanced Light Source is supported by the Director, Office of Science, Office of 
Basic Energy Sciences, of the U.S. Department of Energy under Contract No. DE-AC02$05 \mathrm{CH} 11231$.

\section{Notes and References}

[1] J. Qiao, Y. Liu, F. Hong, J. Zhang, A review of catalysts for the electroreduction of carbon dioxide to produce low-carbon fuels., Chem. Soc. Rev. 43 (2014) 631-75. doi:10.1039/c3cs60323g.

[2] J.S. Sawyer, Man-made Carbon Dioxide and the "Greenhouse" Effect, Nature. 239 (1972) 23-26. doi:10.1038/239023a0.

[3] T. Volk, The World' s Greatest Environmental Challenge, The MIT Press, Cambridge, Massachusetts, 2008.

[4] G. a. Olah, A. Goeppert, G.K.S. Prakash, Chemical recycling of carbon dioxide to methanol and dimethyl ether: From greenhouse gas to renewable, environmentally carbon neutral fuels and synthetic hydrocarbons, J. Org. Chem. 74 (2009) 487-498. doi:10.1021/jo801260f.

[5] N.S. Spinner, J. a. Vega, W.E. Mustain, Recent progress in the electrochemical conversion and utilization of CO2, Catal. Sci. Technol. 2 (2012) 19. doi:10.1039/c1cy00314c.

[6] C. Riplinger, M.D. Sampson, A.M. Ritzmann, P. Kubiak, E.A. Carter, Mechanistic Contrasts between Manganese and Rhenium Bipyridine Electrocatalysts for the Reduction of Carbon Dioxide, J. Am. Chem. Soc. 136 (2014) 16825-16298. doi:doi.org/10.1021/ja508192y.

[7] P. Simon, Y. Gogotsi, B. Dunn, Where Do Batteries End and Supercapacitors Begin?, Sci. Mag. 343 (2014) 1210-1211. doi:10.1126/science.1249625.

[8] J. a. Keith, K. a. Grice, C.P. Kubiak, E. a. Carter, Elucidation of the selectivity of protondependent electrocatalytic $\mathrm{CO} 2$ reduction by fac $-\mathrm{Re}(\mathrm{bpy})(\mathrm{CO}) 3 \mathrm{Cl}$, J. Am. Chem. Soc. 135 (2013) 15823-15829. doi:10.1021/ja406456g.

[9] M. V Vollmer, C.W. Machan, M.L. Clark, W.E. Antholine, J. Agarwal, H.F.S. Iii, et al., Synthesis, Spectroscopy, and Electrochemistry of ( $\alpha$ - Diimine) $\mathrm{M}(\mathrm{CO}) 3 \mathrm{Br}, \mathrm{M}=\mathrm{Mn}, \mathrm{Re}$, Complexes: Ligands Isoelectronic to Bipyridyl Show Di ff erences in CO 2 Reduction, Organometallics. 34 (2015) 3-12. doi:10.1021/om500838z. 
[10] A.Y. Khodakov, W. Chu, P. Fongarland, Advances in the development of novel cobalt Fischer-Tropsch catalysts for synthesis of long-chain hydrocarbons and clean fuels, Chem. Rev. 107 (2007) 1692-1744. doi:10.1021/cr050972v.

[11] Y. Tamaki, T. Morimoto, K. Koike, O. Ishitani, Photocatalytic CO2 reduction with high turnover frequency and selectivity of formic acid formation using $\mathrm{Ru}$ (II) multinuclear complexes, Proc. Natl. Acad. Sci. 109 (2012) 15673-15678.

doi:10.1073/pnas.1118336109.

[12] M.D. Sampson, A.D. Nguyen, K. a Grice, C.E. Moore, A.L. Rheingold, C.P. Kubiak, Manganese catalysts with bulky bipyridine ligands for the electrocatalytic reduction of carbon dioxide: eliminating dimerization and altering catalysis., J. Am. Chem. Soc. 136 (2014) 5460-71. doi:10.1021/ja501252f.

[13] R.J. Haines, R.E. Wittrig, C.P. Kubiak, Electrocatalytic Reduction of Carbon Dioxide by the Binuclear Copper Complex [Cu2(6-(diphenylphosphino)-2,2'bipyridyl)2(MeCN)2[PF6]2, Inorg. Chem. 33 (1994) 4723-4728. doi:10.1021/ic00099a024.

[14] M. Bourrez, F. Molton, S. Chardon-Noblat, A. Deronzier, [Mn(bipyridyl)(CO)3Br]: An abundant metal carbonyl complex as efficient electrocatalyst for $\mathrm{CO} 2$ reduction, Angew. Chemie - Int. Ed. 50 (2011) 9903-9906. doi:10.1002/anie.201103616.

[15] D.C. Grills, Y. Matsubara, Y. Kuwahara, S.R. Golisz, D. a Kurtz, B. a Mello, Electrocatalytic CO 2 Reduction with a Homogeneous Catalyst in Ionic Liquid: High Catalytic Activity at Low Overpotential, J. Phys. Chem. Lett. 5 (2014) 2033-2038. doi:10.1021/jz500759x.

[16] M. Alvarez-Guerra, J. Albo, E. Alvarez-Guerra, A. Irabien, Ionic liquids in the electrochemical valorisation of CO 2, Energy Environ. Sci. 8 (2015) 2574-2599. doi:10.1039/C5EE01486G.

[17] J. Hawecker, J.-M. Lehn, R. Ziessel, Electrocatalytic reduction of carbon dioxide mediated by $\operatorname{Re}($ bipy $)(\mathrm{CO}) 3 \mathrm{Cl}$ (bipy = 2,2?-bipyridine), J. Chem. Soc. Chem. Commun. 984 (1984) 328. doi:10.1039/c39840000328.

[18] J.M. Smieja, C.P. Kubiak, Re(bipy-tBu)(CO)3Cl-improved catalytic activity for reduction of carbon dioxide: IR-spectroelectrochemical and mechanistic studies, Inorg. Chem. 49 (2010) 9283-9289. doi:10.1021/ic1008363.

[19] C.W. Machan, M.D. Sampson, S. a Chabolla, T. Dang, P. Kubiak, Developing a Mechanistic Understanding of Molecular Electrocatalysts for CO 2 Reduction using Infrared Spectroelectrochemistry, Organometallics. 33 (2014) 4550-4559. doi:doi.org/10.1021/om500044a. 
[20] C.W. Machan, C.J. Stanton, J.E. Vandezande, G.F. Majetich, H.F. Schaefer, C.P. Kubiak, et al., Electrocatalytic Reduction of Carbon Dioxide by $\mathrm{Mn}(\mathrm{CN})\left(2,2^{\prime}\right.$-bipyridine $)(\mathrm{CO}) 3$ : CN Coordination Alters Mechanism, Inorg. Chem. 2 (2015).

doi:10.1021/acs.inorgchem.5b01715.

[21] E.E. Benson, C.P. Kubiak, Structural investigations into the deactivation pathway of the CO2 reduction electrocatalyst $\operatorname{Re}($ bpy $)(\mathrm{CO}) 3 \mathrm{Cl}$, Chem. Commun. 48 (2012) 7374. doi:10.1039/c2cc32617e.

[22] M. Goichi, K. Segawa, S. Suzuki, S. Toyota, Improved synthesis of 1,8-diiodoanthracene and its application to the synthesis of multiple phenylethynyl-substituted anthracenes, Synthesis (Stuttg). (2005) 2116-2118. doi:10.1055/s-2005-869999.

[23] M. Pérez-Trujillo, I. Maestre, C. Jaime, A. Alvarez-Larena, J.F. Piniella, A. Virgili, Enantioselective preparation and structural and conformational analysis of the chiral solvating agent $\alpha, \alpha^{\prime}$-bis(trifluoromethyl)-1,8- anthracenedimethanol, Tetrahedron Asymmetry. 16 (2005) 3084-3093. doi:10.1016/j.tetasy.2005.08.005.

[24] B.J. Liddle, S. V. Lindeman, D.L. Reger, J.R. Gardinier, A thallium mediated route to $\sigma$ arylalkynyl complexes of bipyridyltricarbonylrhenium(I), Inorg. Chem. 46 (2007) 84848486. doi:10.1021/ic701406y.

[25] Allen J. Bard; Larry A. Faulkner, Wiley: Electrochemical Methods: Fundamentals and Applications, 2nd Edition, 2nd ed., Wiley, 2001.

[26] J.M. Smieja, E.E. Benson, B. Kumar, K. a Grice, C.S. Seu, A.J.M. Miller, et al., Kinetic and structural studies, origins of selectivity, and interfacial charge transfer in the artificial photosynthesis of CO, Proc. Natl. Acad. Sci. 109 (2012) 15646-15650.

doi:10.1073/pnas.1119863109/-

/DCSupplemental.www.pnas.org/cgi/doi/10.1073/pnas.1119863109.

[27] G. Sahara, O. Ishitani, Efficient Photocatalysts for CO 2 Reduction, Inorg. Chem. 54 (2015) 5096-5104. doi:10.1021/ic502675a. 